\title{
PENGARUH DEEP BACK MASSAGE TERHADAP NYERI PERSALINAN KALA I FASE AKTIF IBU INPARTU PRIMIGRAVIDA DI BPS ENDANG ADJI, Amd.Keb
}

\author{
Astria Blandina Gaidaka \\ Email : astriagaidaka@gmail.com \\ Hp : 081333248016
}

\begin{abstract}
ABSTRAK
Pendahuluan: Metode deep back massage merupakan salah satu metode pengendalian nyeri berupa pijitan / massage dengan menekan daerah sakrum secara mantap dengan telapak tangan, lepaskan dan tekan lagi, begitu seterusnya. Pasien dalam keadaan berbaring miring, dilakukan selama \pm 20 menit selama kontraksi ( \pm 6 kali kontraksi). Tujuan penelitian ini untuk mengetahui pengaruh deep back massage terhadap nyeri persalinan kala I fase aktif ibu inpartu primigravida. Metode: Jenis penelitian yang digunakan adalah experimental design dengan rancang bangun control group pretest-post test. Besar sampel adalah 26 orang, dengan teknik allocation random sampling kemudian dibagi menjadi 2 kelompok yaitu 13 orang kelompok intevensi dan 13 orang kelompok kontrol. Penelitian ini dilakukan dengan cara mengobservasi nyeri persalinan selama kala I fase aktif ibu inpartu primigravida, dari tanggal 21 Februari - 31 Mei 2012. Uji analisis yang digunakan adalah wilcoxon macth pairs test. Hasil: Berdasarkan hasil uji wilcoxon macth pairs test menunjukkan nilai z hitung sebesar $\quad-2,179$, dengan nilai signifikansi 0,029 $<0,05$. Diskusi : Maka dapat disimpulkan bahwa ada pengaruh deep back massage terhadap nyeri persalinan kala I fase aktif ibu inpartu primigravida. Pemberian deep back massage yang tepat dan sering, yang dilakukan oleh pendamping persalinan maupun keluarga akan mengurangi nyeri persalinan kala I fase aktif.
\end{abstract}

Kata Kunci : deep back massage, nyeri persalinan, inpartu, primigravida

\begin{abstract}
Introdution: Deep back massage method is a method of paining control through massaging by pressing sacrum area carefully with palms, holding off and pressing again, and so on. The patient lays down in oblique position, it is done for 20 minutes during contraction ( \pm 6 times contraction). The aim of this research is to know the effect of deep back massage toward birth pain period I inpartu primigravida active fase. Methode: This kind of research applied is experimental design with control group pre-post test. The number of sample is 26 persons, with allocation random sampling technique then it is divided into two groups that consist of 13 persons in intervention group and 13 persons in control group. The research is done by observing the birth pain during the period I active fase of mother inpartu primigravida from 21 February to 31 Mei 2012. Result: The analysis test which was done is wilcoxon match pairs test. According to the result by wilcoxon signed rank test, shows that $z$ counting score is as big as -2,179 with significance score 0,029 < 0,050. Discussions: Thus, it can be conclude that there is an effect to deep back massage toward birth pain period I active mother inpartu primigravida fase. It means that applying deep back massage can given by family and nurse, it can reduce the birth pain period I active fase.
\end{abstract}

Key word : deep back massage, birth pain, inpartu, primigravida 


\section{PENDAHULUAN}

Persalinan adalah proses pengeluaran hasil konsepsi, yang dapat hidup ke dunia luar, dari rahim melalui jalan lahir atau dengan jalan lain (Prawirohardjo,2007). Nyeri persalinan yang lama menyebabkan hiperventilasi dengan frekuensi pernafasan 6070 kali per menit sehingga menurunkan kadar $\mathrm{PaCO}_{2}$ ibu dan peningkatan $\mathrm{pH}$. Apabila kadar $\mathrm{PaCO}_{2}$ ibu rendah, maka kadar $\mathrm{PaCO}_{2}$ janin juga rendah sehingga menyebabkan deselerasi lambat denyut jantung janin, nyeri juga meyebabkan aktivitas uterus yang tidak terkoordinasi yang akan mengakibatkan persalinan lama, yang akhirnya dapat mengancam kehidupan janin dan ibu (Mander,2007).

Deep back massage adalah pijatan lembut dengan menekan daerah sakrum menggunakan telapak tangan. Pijat ini diberikan dengan menggunakan dasar teori gate control yang dikemukakan oleh Melzack dan Wall (1997). Pijatan yang diberikan akan merangsang saraf diameter besar yang menyebabkan gate control menutup dan impuls nyeri tidak diteruskan ke korteks serebral, sehingga rasa nyeri yang dirasakan akan berkurang.

Nyeri persalinan dapat diatasi dengan metode farmakologi dan non farmakologi. Metode farmakologi terdiri dari analgesia (inhalasi dan opioid) dan analgesia/anestesia regional (anestesia spinal dan analgesia epidural), sedangkan metode non farmakologi terdiri dari relaksasi, hipnoterapi, imajinasi, massage, music, akupuntur, transcutaneous electrical nerve stimulation (TENS), hidroterapi, serta posisi, postur dan ambulasi.

\section{METODE}

Penelitian yang dilakukan adalah penelitian quasy experimental design yaitu untuk mengetahui keefektifitas metode deep back massage terhadap nyeri persalinan kala I fase aktif ibu primigravida.

Penelitian ini menggunakan rancang bangun control group pretest-posttest design.

Populasi dalam penelitian ini adalah semua ibu primigravida yang dilihat dari hari perkiraan lahir (HPL) pada bulan Februari Mei 2012 di BPS Ny. Endang Adji, Amd.Keb sebanyak 26 orang.
Sampel dalam penelitian ini adalah ibu primigravida yang menurut hari perkiraan lahir (HPL) pada bulan Februari - Mei 2012 di BPS Ny. Endang Adji, Amd.Keb sebanyak 26 orang. Kriteria Inklusi : Ibu inpartu primigravida kala I fase aktif, persalinan normal tanpa komplikasi, hubungan keluarga yang harmonis dan ibu bersedia untuk diteliti.

Pengambilan sampel dilakukan dengan teknik allocation random sampling. Sampel yang berjumlah 26 orang dibagi menjadi dua kelompok yaitu kelompok intervensi sebanyak 13 orang dan kelompok kontrol sebanyak 13 orang.

Dalam penelitian ini variabel independennya adalah deep back massage dan variabel dependennya adalah tingkat nyeri persalinan.

Data yang telah terkumpul dilakukan pengolahan awal yaitu: Editing adalah memeriksa daftar lembar observasi yang telah diisi. Coding adalah mengklasifikasi jawaban dari lembar observasi kedalam kategori. Scoring adalah penentuan jumlah skor. Tabulating adalah dengan membuat tabel sesuai dengan analisis yang dibutuhkan. Kemudian data diuji dengan program SPSS computer menggunakan uji wilcoxon signed rank test untuk mengetahui pengaruh deep back massage terhadap nyeri persalian kala I fase aktif ibu inpartu primigravida.

\section{HASIL}

Bidan Praktek Swasta (BPS) Ny. Endang Adji, Amd.Keb terletak di Jalan Rungkut Mejoyo VI/12 Surabaya. Lokasinya di daerah perumahan sehingga memudahkan warga sekitar untuk menjangkau. Tenaga kesehatan yang dimiliki BPS Ny. Endang Adji, Amd.Keb berjumlah 5 orang, yang terdiri dari 4 orang bidan. Program yang ada di

\begin{tabular}{|c|c|c|c|c|}
\hline \multirow{2}{*}{$\begin{array}{l}\text { Pendi } \\
\text { dikan }\end{array}$} & \multicolumn{2}{|c|}{$\begin{array}{l}\text { Kelompok } \\
\text { Intervensi }\end{array}$} & \multicolumn{2}{|c|}{$\begin{array}{c}\text { Kelompok } \\
\text { Kontrol }\end{array}$} \\
\hline & $\begin{array}{c}\text { Frekuen } \\
\text { si }\end{array}$ & $\begin{array}{c}\text { Presen } \\
\text { tase }\end{array}$ & $\begin{array}{c}\text { Freku } \\
\text { ensi }\end{array}$ & $\begin{array}{c}\text { Presen } \\
\text { tase }\end{array}$ \\
\hline SD & - & - & 1 & $7,7 \%$ \\
\hline SMP & 3 & $\begin{array}{c}23,1 \\
\%\end{array}$ & 5 & $\begin{array}{c}38,5 \\
\%\end{array}$ \\
\hline SMA & 9 & $\begin{array}{c}69,2 \\
\%\end{array}$ & 7 & $\begin{array}{c}53,8 \\
\%\end{array}$ \\
\hline PT & 1 & $7,7 \%$ & - & - \\
\hline Total & 13 & $100 \%$ & 13 & $100 \%$ \\
\hline
\end{tabular}

BPS Ny. Endang Adji, Amd.Keb adalah KB, 
pemeriksaan kandungan, persalinan bidan dan imunisasi (BCG dan campak dilayani setiap sabtu, sedangkan hepatitis B, polio, DPT dilayani setiap hari). Fasilitas yang dimiliki oleh BPS Ny. Endang Adji, Amd.Keb adalah VK 1 ruangan 2 bed, 2 ruangan nifas, klinik 1 ruangan serta kamar obat 1 ruangan.

Tabel 1 Distribusi frekuensi ibu inpartu berdasarkan umur di BPS Ny.Endang Adji,Amd.Keb,Surabaya,bulan FebruariMei 2012.

\begin{tabular}{|c|c|c|c|c|}
\hline \multirow{2}{*}{ Umur } & \multicolumn{2}{|c|}{$\begin{array}{l}\text { Kelompok } \\
\text { Intervensi }\end{array}$} & \multicolumn{2}{|c|}{$\begin{array}{c}\text { Kelompok } \\
\text { Kontrol }\end{array}$} \\
\hline & $\begin{array}{c}\text { Freku } \\
\text { ensi }\end{array}$ & $\begin{array}{c}\text { Presen } \\
\text { tase }\end{array}$ & $\begin{array}{c}\text { Freku } \\
\text { ensi }\end{array}$ & $\begin{array}{c}\text { Presen } \\
\text { tase }\end{array}$ \\
\hline$<20$ & 3 & $\begin{array}{c}23,1 \\
\%\end{array}$ & 2 & $\begin{array}{c}15,4 \\
\%\end{array}$ \\
\hline $\begin{array}{l}20- \\
25\end{array}$ & 3 & $\begin{array}{c}23,1 \\
\%\end{array}$ & 8 & $\begin{array}{c}61,5 \\
\%\end{array}$ \\
\hline $26-30$ & 5 & $\begin{array}{c}38,4 \\
\%\end{array}$ & 2 & $\begin{array}{c}15,4 \\
\%\end{array}$ \\
\hline$>30$ & 2 & $\begin{array}{c}15,4 \\
\%\end{array}$ & 1 & $7,7 \%$ \\
\hline Total & 13 & $100 \%$ & 13 & $100 \%$ \\
\hline
\end{tabular}

Pada penelitian ini, kelompok intervensi dalam kelompok umur <20 tahun berjumlah 3 orang $(23,1 \%), 20-25$ tahun berjumlah 3 orang $(23,1 \%), 26-30$ tahun berjumlah 5 orang $(38,4 \%)$ dan $>30$ tahun berjumlah 2 orang $(15,4 \%)$. Sedangkan pada kelompok kontrol, dalam kelompok umur $<20$ tahun berjumlah 2 orang $(15,4 \%), 20-25$ tahun berjumlah 8 orang $(61,5 \%), 26-30$ tahun berjumlah 2 orang $(15,4 \%)$ dan $>30$ tahun berjumlah 1 orang $(7,7 \%)$.

Tabel 2 Distribusi frekuensi ibu inpartu berdasarkan pendidikan di BPS Ny.Endang Adji,Amd.Keb,Surabaya,bulan FebruariMei 2012.

Responden kelompok intervensi yang lulusan SMP 3 orang $(23,1 \%)$, SMA 9 orang $(69,2 \%)$ dan PT 1 orang $(7,7 \%)$. Sedangkan, responden kelompok kontrol yang lulusan SD 1 orang (7,7\%), SMP 5 orang $(38,5 \%)$, SMA 7 orang.

Sumber : Data Primer, 2012
Tabel 3 Distribusi frekuensi ibu inpartu berdasarkan pekerjaan di BPS Ny.Endang Adji,Amd.Keb,Surabaya,bulan FebruariMei 2012.

\begin{tabular}{ccccc} 
& \multicolumn{2}{c}{ Kelompok } & \multicolumn{2}{c}{ Kelompok } \\
Pekerjaan & \multicolumn{2}{c}{ Intervensi } & \multicolumn{2}{c}{ Kontrol } \\
& Freku & Presenta & Frekue & Presenta \\
ensi & se & nsi & se \\
\hline IRT & 8 & $61,5 \%$ & 5 & $38,5 \%$ \\
PNS & 1 & $7,7 \%$ & - & - \\
Wiraswasta & - & - & 2 & $15,4 \%$ \\
$\begin{array}{c}\text { Karyawan/b } \\
\text { uruh }\end{array}$ & 4 & $30,8 \%$ & 6 & $46,1 \%$ \\
\hline Total & 13 & $100 \%$ & 13 & $100 \%$ \\
\hline Sumber
\end{tabular}

Sumber : Data Primer, 2012

Tabel 4 Tingkat Intensitas Nyeri Ibu Inpartu Sebelum dan Sesudah Intervensi

\begin{tabular}{ccccc}
\hline Intensitas & \multicolumn{5}{c}{ Sebelum } & \multicolumn{2}{c}{ Sesudah } \\
Nyeri & $\begin{array}{c}\text { Freku } \\
\text { ensi }\end{array}$ & $\begin{array}{c}\text { Presen } \\
\text { tase }\end{array}$ & $\begin{array}{c}\text { Freku } \\
\text { ensi }\end{array}$ & $\begin{array}{c}\text { Presen } \\
\text { tase }\end{array}$ \\
\hline Tidak & - & - & - & - \\
Nyeri & & & & $38,5 \%$ \\
Nyeri & - & - & 5 & $36,1 \%$ \\
$\begin{array}{c}\text { Ringan } \\
\text { Nyeri }\end{array}$ & 2 & $15,4 \%$ & 6 & $46 \%$ \\
$\begin{array}{c}\text { Sedang } \\
\text { Nyeri Berat } \\
\text { Terkontrol }\end{array}$ & 11 & $84,6 \%$ & 2 & $15,4 \%$ \\
$\begin{array}{c}\text { Nyeri Berat } \\
\text { Tidak }\end{array}$ & - & & & \\
Terkontrol & & & - & - \\
\hline Total & 13 & $100 \%$ & 13 & $100 \%$ \\
\hline Sumber: Dat Prim
\end{tabular}

Sumber : Data Primer,2012

Reponden kelompok intervensi sebagai ibu rumah tangga sebanyak 8 orang $(61,5 \%)$, PNS 1 orang $(7,7)$, karyawan/buruh 4 orang (30,8\%). Sedangkan, responden kelompok kontrol ibu rumah tangga 5 orang $(38,5 \%)$, wiraswasta 2 orang $(15,4 \%)$ dan karyawan/buruh 6 orang $(46,1 \%)$. 
Tabel 5 Tingkat Intensitas Nyeri Ibu Inpartu Pada Kelompok Kontrol

\begin{tabular}{ccccc}
\hline Intensitas & \multicolumn{5}{c}{ Sebelum } & \multicolumn{2}{c}{ Sesudah } \\
Nyeri & $\begin{array}{c}\text { Freku } \\
\text { ensi }\end{array}$ & $\begin{array}{c}\text { Prese } \\
\text { ntase }\end{array}$ & $\begin{array}{c}\text { Frek } \\
\text { uensi }\end{array}$ & Presentase \\
\hline Tidak & - & - & - & - \\
Nyeri & & & & $15,4 \%$ \\
Nyeri & - & - & 2 & $23,1 \%$ \\
$\begin{array}{c}\text { Ringan } \\
\text { Nyeri }\end{array}$ & 4 & $\begin{array}{c}30,8 \\
\%\end{array}$ & 3 & $61,5 \%$ \\
$\begin{array}{c}\text { Sedang } \\
\text { Nyeri Berat } \\
\text { Terkontrol } \\
\text { Nyeri Berat } \\
\text { Tidak }\end{array}$ & 9 & $\begin{array}{c}69,2 \\
\%\end{array}$ & 8 & \\
Terkontrol & - & - & - & - \\
\hline Total & 13 & $\begin{array}{c}100 \\
\%\end{array}$ & 13 & $100 \%$ \\
\hline
\end{tabular}

Sumber : Data Primer,2012

Berdasarkan hasil penelitian, jumlah ibu inpartu pada kelompok intervensi sebelum dilakukan intervensi berada pada skala nyeri sedang yaitu 2 orang $(15,4 \%)$ dan nyeri berat terkontrol yaitu 11 orang $(84,6 \%)$. Setelah dilakukan intervensi intensitas ibu inpartu mengalami perubahan menjadi nyeri ringan 5 orang $(38,5 \%)$, nyeri sedang 6 orang $(46,1 \%)$ dan nyeri berat terkontrol berjumlah 2 orang $(15,4 \%)$.

Berdasarkan hasil penelitian, jumlah ibu inpartu pada kelompok kontrol sebelum melakukan intervensi, berada pada intensitas nyeri sedang 4 orang $(30,8 \%)$ dan nyeri berat terkontrol 9 orang $(69,2 \%)$. Sedangkan, setelah melakukan intervensi didapatkan nyeri ringan 2 orang $(15,4 \%)$, nyeri sedang 3 orang $(23,1 \%)$ dan nyeri berat terkontrol 8 orang $(61,5 \%)$.
Tabel 6 Pengaruh Deep Back Massage Terhadap Nyeri Persalinan Kala I Fase Aktif Ibu Inpartu Primigravida

\begin{tabular}{|c|c|c|c|c|}
\hline \multirow{2}{*}{$\begin{array}{c}\text { Intensit } \\
\text { as } \\
\text { Nyeri }\end{array}$} & \multicolumn{2}{|c|}{$\begin{array}{c}\text { Sesudah } \\
\text { Kelompok } \\
\text { Intervensi }\end{array}$} & \multicolumn{2}{|c|}{$\begin{array}{l}\text { Sesudah } \\
\text { Kelompok } \\
\text { Kontrol }\end{array}$} \\
\hline & $\begin{array}{c}\text { Frekue } \\
\text { nsi }\end{array}$ & $\begin{array}{c}\text { Present } \\
\text { ase }\end{array}$ & $\begin{array}{c}\text { Frekue } \\
\text { nsi }\end{array}$ & $\begin{array}{c}\text { Present } \\
\text { ase }\end{array}$ \\
\hline $\begin{array}{l}\text { Tidak } \\
\text { Nyeri }\end{array}$ & - & - & - & - \\
\hline $\begin{array}{l}\text { Nyeri } \\
\text { Ringan }\end{array}$ & 5 orang & $38,5 \%$ & $\begin{array}{c}2 \\
\text { orang }\end{array}$ & $15,4 \%$ \\
\hline $\begin{array}{l}\text { Nyeri } \\
\text { Sedang }\end{array}$ & 6 orang & $46,1 \%$ & $\begin{array}{c}3 \\
\text { orang }\end{array}$ & $23,1 \%$ \\
\hline $\begin{array}{c}\text { Nyeri } \\
\text { Berat } \\
\text { Terkon } \\
\text { trol }\end{array}$ & 2 orang & $15,4 \%$ & $\begin{array}{c}8 \\
\text { orang }\end{array}$ & $61,5 \%$ \\
\hline $\begin{array}{c}\text { Nyeri } \\
\text { Berat } \\
\text { Tidak } \\
\text { Terkon } \\
\text { trol }\end{array}$ & - & - & - & - \\
\hline Total & $\begin{array}{c}13 \\
\text { orang } \\
-2,179\end{array}$ & $100 \%$ & $\begin{array}{c}13 \\
\text { orang } \\
\alpha: 0\end{array}$ & $\begin{array}{l}100 \% \\
29\end{array}$ \\
\hline
\end{tabular}

Sumber : Data Primer,2012

Berdasarkan hasil uji menggunakan wilcoxon match pairs test dengan tingkat kepercayaan 0,050 diperoleh hasil z hitung 2,179. Hasil penelitian menunjukkan nilai signifikansi $0,029<0,050$. Hal ini menunjukkan ada pengaruh deep back massage terhadap nyeri persalinan kala I fase aktif ibu inpartu primigravida

\section{PEMBAHASAN}

Nyeri Persalinan Kala I Fase Aktif Ibu Inpartu Primigravida yang Dilakukan Deep Back Massage

Berdasarkan hasil penelitian yang telah dilakukan terhadap 13 ibu inpartu pada kelompok intervensi di BPS Ny. Endang Adji,Amd.Keb, diperoleh hasil sebagian besar ibu inpartu sebelum dilakukan intervensi berada dalam rentang intensitas nyeri sedang sebanyak 2 orang $(15,4 \%)$, nyeri berat terkontrol yaitu sebesar 11 orang $(84,6 \%)$, setelah dilakukan intervensi intensitas nyeri ibu inpartu yang tetap pada nyeri berat terkontrol berjumlah 2 orang $(15,4 \%)$, 
intensitas nyeri yang berkurang menjadi nyeri sedang berjumlah 6 orang $(46,1 \%)$ sedangkan intensitas nyeri yang berkurang menjadi nyeri ringan berjumlah 5 orang $(38,5 \%)$.

Nyeri persalinan disebabkan karena terjadi perubahan-perubahan yaitu dilatasi serviks dan segmen bawah uterus serta distensi korpus uteri. Pengendalian nyeri persalinan dapat dilakukan dengan deep back massage. Metode ini akan menutup gate control sehingga nyeri akan berkurang (Kuswandy,2009). Menurut Mogan (2007), pijatan yang diberikan akan merangsang tubuh melepaskan senyawa endorphin yang merupakan pereda sakit alami. Tindakan ini perlu diterapkan oleh pendamping persalinan untuk memberikan kenyamanan pengasuhan selama kehamilan dan persalinan.

Rentang usia kehamilan dan persalinan yang aman adalah 20-30 tahun. Ibu yang melahirkan pertama kali pada usia tua akan lebih mengalami nyeri persalinan dibandingkan dengan yang muda. Sesuai hasil penelitian yang di dapat perubahan intensitas dari nyeri berat terkontrol menjadi nyeri sedang berada dalam rentang umur 26-30 tahun, hal ini menunjukkan bahwa dari faktor umur ibu inpartu telah siap menghadapi persalinan. Nyeri persalinan juga di pengaruhi oleh tingkat pendidikan seseorang,dimana semakin tinggi tingkat pendidikan seseorang akan berpengaruh pada tingkat pengetahuannya serta akan mempengaruhi persepsi terhadap nyeri persalinan.Sesuai dengan hasil penelitian sebagian responden berpendidikan SMA.

\section{Nyeri Persalinan Kala I Fase Aktif Ibu Inpartu Primigravida yang Tidak Dilakukan Deep Back Massage}

Berdasarkan hasil penelitian yang telah dilakukan terhadap 13 ibu inpartu pada kelompok kontrol di BPS Ny. Endang Adji,Amd.Keb, diperoleh hasil sebagian besar ibu inpartu berada dalam intensitas nyeri berat terkontrol yaitu 8 orang $(61,5 \%)$.

Sebagian besar ibu inpartu pada kelompok kontrol menggunakan teknik pernapasan dan pendampingan suami. Sesuai teori yang dikemukan oleh Andriana (2011), bahwa teknik pernapasan untuk proses persalinan didasarkan pada konsentrasi yang dibutuhkan ibu hamil untuk mengatur napasnya. Saat berkontraksi, secara otomatis otak mengirim respon ke sekujur tubuh untuk menahan nyeri. Kita dilatih oleh respons nyeri ini untuk mengendalikannya lewat napas yang teratur dan tidak tertahankan (Andriana,2011). Adapun pendapat dari Sulastomo (2010),mengatakan bahwa suami bagi istri yang bersiap untuk melahirkan bagai onggokan mata air yang bisa diminum ketika istri dalam keadaan haus. Ketika suami hadir di dekat istri yang siap untuk melahirkan istri akan merasa lebih tenang.

Kehadiran suami disisi istrinya bukan hanya menemani sang istri tetapi juga membuktikan rasa sayang kepada sang istri sehingga istri akan merasa lebih tenang. Banyak hal yang dapat dilakukan suami antara lain memberi dorongan, semangat serta mengusap punggung istri. Perasaan yang tenang membuat tubuh mengeluarkan endorphin yaitu pereda sakit alami. Sehingga rasa nyeri ibu inpartu akan berkurang.

\section{Pengaruh Deep Back Massage Terhadap Nyeri Persalinan Kala I Fase Aktif Ibu Inpartu Primigravida}

Data analisis dengan menggunakan uji statistik wilcoxon match pairs test dengan tingkat kepercayaan 0,050 diperoleh z hitung 2,179 . Hasil penelitian menunjukkan nilai signifikansi $0,029<0,050$. Ini menunjukkan ada pengaruh deep back massage terhadap nyeri persalinan kala I fase aktif ibu inpartu primigravida.

Nyeri persalinan dapat di blok dengan melakukan pijatan / massage yaitu dengan teknik deep back massage. Pijatan yang diberikan akan merangsang saraf diameter besar yang menyebabkan gate control menutup, sehingga akan menghambat impuls dari serabut berdiameter kecil di area subtantia gelatinosa maka sensasi yang dibawa serabut kecil akan berkurang atau tidak dihantarkan ke otak dan tubuh tidak akan merasakan nyeri (Tamsuri,2007).

Pijatan yang diberikan untuk mengurangi nyeri persalinan harus diberikan pada tempat yang tepat dan dilakukan pada awal kontraksi sehingga ibu inpartu dapat merasakan manfaat dari pijatan yang diberikan.

\section{SIMPULAN}

Intensitas nyeri pada sebagian besar ibu inpartu kelompok intervensi sebelum dilakukan deep back massage berada dalam 
rentang intensitas nyeri berat terkontrol yaitu $84,6 \%$, sedangkan setelah dilakukan intervensi berkurang menjadi nyeri sedang sebanyak $46,1 \%$.

Intensitas nyeri pada sebagian besar ibu inpartu kelompok kontrol berada dalam rentang intensitas nyeri berat terkontrol sebesar $69,2 \%$, sedangkan setelah dilakukan tindakan kontrol intensitas nyeri berkurang sebesar $61,5 \%$.

Ada pengaruh antara deep back massage terhadap nyeri persalinan kala I fase aktif ibu inpartu primigravida di BPS $\mathrm{Ny}$. Endang Adji, Amd.Keb.

\section{SARAN}

Hasil penelitian ini dapat digunakan sebagai data dasar bagi tenaga keperawatan ataupun kebidanan yang ingin meneliti tentang deep back massage dan dapat dikembangkan sehingga hasilnya lebih spesifik. Untuk tenaga kesehatan di klinik maupun di rumah sakit dapat menggunakan teknik deep back massage dalam mengurangi nyeri persalinan kala I fase aktif. Hasil penelitian ini dapat dijadikan acuan dan dapat diintegrasikan kedalam mata kuliah asuhan ibu bersalin sebagai pengembangan ilmu. Meningkatkan pemahaman bagi keluarga maupun pendamping persalinan tentang cara yang benar dalam menerapkan metode deep back massage sehingga dapat mengurangi nyeri persalinan.

\section{DAFTAR PUSTAKA}

Amrin, Kiat-Kiat Melahirkan Nyaman Tanpa Rasa Sakit Yang Menakutkan, (Jakarta:Rineka cipta, 2010), 154.

Andriana, Melahirkan Tanpa Rasa Sakit, (Jakarta: PT.Bhuana Ilmu Populer,2011),107.

Danuatmaja \& Meiliasari, Persalinan Normal Tanpa Rasa Sakit,(Jakarta : Puspa swara,2007), 67.

Kuswandy, Keajaiban Hypno-birthing, (Jakarta : Pustaka Bunda, 2011), 18.

Mander, Nyeri Persalinan, (Jakarta:ECG, 2007), 21, 77, 89

Mogan, Metode Melahirkan Secara Aman,Mudah \& Nyaman, (Jakarta : Buana Ilmu Populer,2007)138.

Prawirohardjo, Pelayanan Kesehatan Maternal dan Neonatal, (Jakarta :
Yayasan Bina Pustaka sarwono Prawirohardjo, 2007), 100.

.Tamsuri, Konsep \& Penatalaksanaan Nyeri, (Jakarta : ECG, 2007), 1, 5, 13, 25. 